\title{
SISTEMA ÚNICO DE SAÚDE: UTOPIA OU REALIDADE?
}

\section{UNIFIED HEALTH SYSTEM: SOCIAL ALIENATION OR REALITY?}

Técia Maria Santos Carneiro e Cordeiro

Carmen Lieta Ressurreição dos Santos

José Nunes Carneiro Neto
Universidade Federal da Bahia (UFBA). E-mail:

teciamarya@yahoo.com.br

Universidade Estadual de Feira de Santana (UEFS). E-mail:

carmenlieta@hotmail.com

Universidade Estadual de Feira de Santana (UEFS). E-mail: jnunes.neto@yahoo.com.br

\section{Abstract}

This study aims to: to analyze of scientific evidence through the NHS as a utopia or reality and describe the profile of scientific production analyzed. This is a systematic review, was of exploratory nature descriptive with qualitative approach and support quantitative. The results indicate about the profile of scientific production: publishing mostly in the period 2007-2010 (65\%), in the journal Science \& Collective Health (28\%), by professionals in Collective Health (37\%), with approach methodological quality (100\%), held in the state of Rio de Janeiro (28\%) and the Southeast region (55\%). What about the NHS, utopia is considered the following aspects: principles and guidelines as universalization, equity, integrity, decentralization, and social control, the publicprivate mix and the concept of health. It is considered that the NHS needs to get over all these utopias making them realizable, by complying with all legislations and rules in the Brazilian health system.

Keywords: UNIFIED HEALTH SYSTEM; HEALTH SYSTEMS; SOCIAL ALIENATION. 


\section{Introdução}

"O Sistema Único de Saúde (SUS) é um dos maiores sistemas públicos de saúde do mundo, sendo o único a garantir assistência integral e completamente gratuita para a totalidade da população". ${ }^{1}$ É fruto de uma grande mobilização social e sustentado pela redemocratização dos anos 80, que foi consolidada em Reforma Sanitária Brasileira (RSB). ${ }^{2}$

O SUS também é entendido como um processo social que não se iniciou com a constituição de 1988 e não termina nem hoje, nem amanhã, porque as reformas são lentas e custosas. Apresenta dimensão social, ideológica e tecnológica entre diversos atores sociais, que há muitos anos são impulsionadas pela RSB. ${ }^{3}$

Segundo Brasil ${ }^{4}$ e Ferreira, ${ }^{5}$ o SUS vem sendo implantado como uma política pública de permanente construção, podendo se renovar continuamente dentro de um processo de mudanças, desde o regime militar em que a população não tinha voz até a Constituição de 1988, passando a ter voz e direito à saúde, por isso o Brasil vive numa constante transformação nos processos econômicos, sociais, culturais e tecnológicos, deixando de ser um processo antiético originado no passado.

Desse modo, observa-se que o SUS concede o direito à saúde e à voz ao povo, regulamentado pela Constituição Federal de 1988 e pelas Leis Orgânicas de Saúde (LOS) - Leis 8.080/90 e $8.142 / 90$, mas na prática isso não acontece, as pessoas estão submissas a decisões políticas e ao não cumprimento das legislações. ${ }^{1,4,5}$

O processo de implementação do SUS, baseado na Constituição Federal de 1988 e regulamentado pelas LOS, teve como principal justificativa a necessidade de melhorar a oferta de serviços, os indicadores de saúde e as condições de acesso, contribuindo para elevar a qualidade de vida da população brasileira. ${ }^{6}$ Partindo para a realidade, houve uma melhora em termos de promoção da saúde no Brasil após o SUS, assim como a disponibilidade de serviços de alta tecnologia. No entanto, ainda se espera mais na oferta e acesso aos serviços de saúde para que venha contribuir de forma efetiva na qualidade de vida da população brasileira.

Além disso, o SUS faz parte de um sistema amplo: o sistema de Seguridade Social. A Seguridade Social assegura a saúde, a previdência e a assistência social, priorizando a universalidade da cobertura e do atendimento a toda população. Suas ações e serviços de saúde integram uma rede regionalizada e hierarquizada, organizada em cada nível de governo e segundo as diretrizes: descentralização, atendimento integral que promove as ações curativas e preventivas e participação da comunidade por meio dos conselhos e conferências de saúde. ${ }^{7}$ Também integra os princípios fundamentais que regem o SUS:

- Universalidade - todas as pessoas têm direito à atenção à saúde e cabe ao Estado garantir esse direito.

- Equidade - ofertar serviços de saúde de acordo com as prioridades de cada área, cobrindo toda a população com os atendimentos.

- Integralidade - todos os serviços de saúde devem está organizados para ofertar todas as ações requeridas para uma atenção integral ao indivíduo.?

O SUS permite o direito à saúde de todos, como afirma a Constituição, isso quer dizer que o usuário não tem direito de pagar pelos serviços públicos porque eles são gratuitos, ou seja, os serviços serão custeados pelos recursos públicos. Para garantir esses recursos, o Governo arrecada do povo, impostos e contribuições destinados e obrigatoriamente utilizados para a seguridade social. Outros impostos podem ser usados também para completar esses recursos. ${ }^{8}$

Esses impostos complementares são das empresas sobre os salários pagos, vendas e lucros, dos trabalhadores sobre seus salários e da venda das loterias. Os recursos são arrecadados pelo Governo Federal, mas, não são do Governo, são públicos, são do povo. ${ }^{8}$

Observa-se que o direito à saúde é garantido a todos, porque paga-se por ele, por meio de impostos em tudo que se compra no Brasil. Nestes 20 anos, o SUS tomou conceitos sinônimos com conteúdos distintos como:

[...] a universalização confundida como simples expansão de oferta, acesso também confundido como cobertura e oferta de serviços, gestão como gerência de serviços enquanto o que se refere à gerência está relacionado à administração, controle social e participação social sem diferenciar controle da sociedade e promoção e fortalecimento de novos espaços públicos para criação de novos sujeitos sociais e o conceito do SUS dependente enquanto se propõe universal e equânime. ${ }^{9}$

Esses conceitos deveriam ser entendidos e não confundidos, porque o SUS está na terceira década de implementação e muitas dificuldades estão associadas a este longo período, o qual poderia 
ter alcançado os objetivos propostos à população brasileira nas legislações.

Maio e Lima $^{10}$ citam que o processo de implementação do SUS tem sido um processo tanto teórico como prático. O teórico fornece elementos empíricos desafiadores para elaboração teórica ou para análise de hipótese no campo de políticas e gestão públicas, incluindo o entendimento da gestão federativa, das possibilidades de gestão democráticas, relações público/privado e sustentabilidade das políticas universais. E o prático, desafia fazer cumprir os princípios e diretrizes do SUS garantindo a saúde para todos.

Esses autores explicitam de maneira correta a situação contemporânea do SUS, que ainda não alcançou as metas propostas, apenas encontrando-se nas legislações, e o desafio de fazer cumpri-lo precisa ser superado por todos os atores sociais que o compõe.

O sucesso do SUS como política pública pode significar um fracasso na atenção às pessoas, já que melhorias no sistema, organização e financiamento não são suficientes para mudar esse paradoxo e assegurar o direito à saúde. ${ }^{11}$ Por isso o SUS necessita ainda de muitos ajustes e permanece em processo de implementação.

\section{Proposição}

Diante de tantos pressupostos acerca do SUS e seu processo de implementação, este estudo tem como proposições descrever o perfil das produções científicas e analisar por meio das evidências científicas a situação contemporânea do SUS.

\section{Material e MÉtodos}

Trata-se de uma revisão sistemática, de caráter exploratório descritivo com abordagem qualitativa, a qual nos permite uma maior familiaridade com o problema da pesquisa, assim como permite aos investigadores aumentar suas experiências em torno de um determinado problema e descrever com exatidão os fatos e fenômenos de determinada realidade. ${ }^{12}$

A coleta de dados deu-se na base eletrônica do SciELO Brasil, LILACS, Google acadêmico e livros. A seleção na base eletrônica seguiu os critérios de inclusão: i) artigos publicados em português; ii) artigos que abordassem o SUS como utopia ou realidade; iii) publicados no período de 2002-2010. Selecionou-se livros como suporte para discussão sem critérios de inclusão. Foram excluídas publicações em inglês e espanhol e que não atendiam ao objeto de estudo.
Os dados foram analisados segundo a análise de conteúdo de Laurence Bardin, ${ }^{13}$ que permite uma análise fiel dos dados por meio da análise das comunicações, visando alcançar por meio de procedimentos sistemáticos e objetivos da descrição do conteúdo das mensagens indicadores que permitam a inferência de conhecimentos relativos às condições de produção dos dados. Como suporte à análise dos dados foi utilizada a abordagem quantitativa, com estatística descritiva em porcentagem.

Durante todo o estudo foram respeitados os aspectos éticos e legais de cada autor, seguindo as normas da Associação Brasileira de Normas Técnicas (ABNT), assim como os direitos autorais segundo a Lei ${ }^{\circ} .9 .610$ de $1998 .{ }^{14}$

\section{Resultados E Discussão}

\section{CENÁRIO DAS PRODUÇÕES CIENTÍFICAS}

O cenário deste estudo é constituído por 11 $(100 \%)$ produções científicas, sendo $82 \%$ artigos científicos e $18 \%$ livros impressos. No gráfico 1 podemos observar o período de publicações das produções científicas, destacando o período de 2007-2010 com 65\%, isso revela que os pesquisadores estão se interessando pela temática na contemporaneidade.

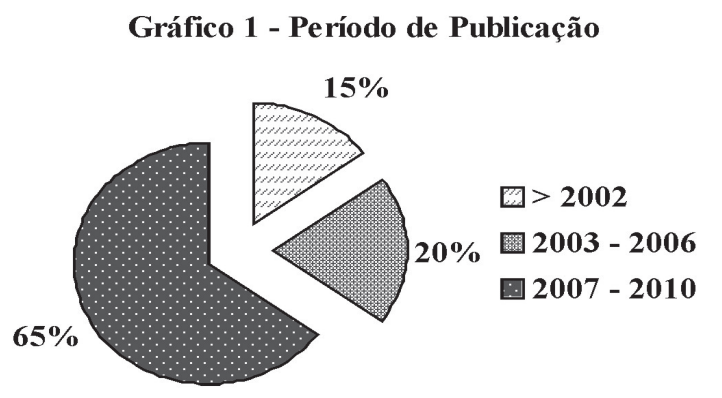

As áreas profissionais dos pesquisadores são diversas, o que mostra a importância do SUS no contexto político, social, biológico, cultural e histórico. A área que se destaca com o maior número de produções científicas é a da Saúde Coletiva (37\%) como apresenta o gráfico 2, o que se esperava pela temática a ser estudada como prioridade nesta área.

Pelo SUS ser uma temática de interesse da maioria dos pesquisadores, as produções científicas são publicadas em vários periódicos, com destaque o periódico Ciência \& Saúde Coletiva $(28 \%)$. O gráfico 3 apresenta os dados.

O lócus das pesquisas (gráfico 4) é destacado nos Estados do Rio de Janeiro (28\%), seguido de 

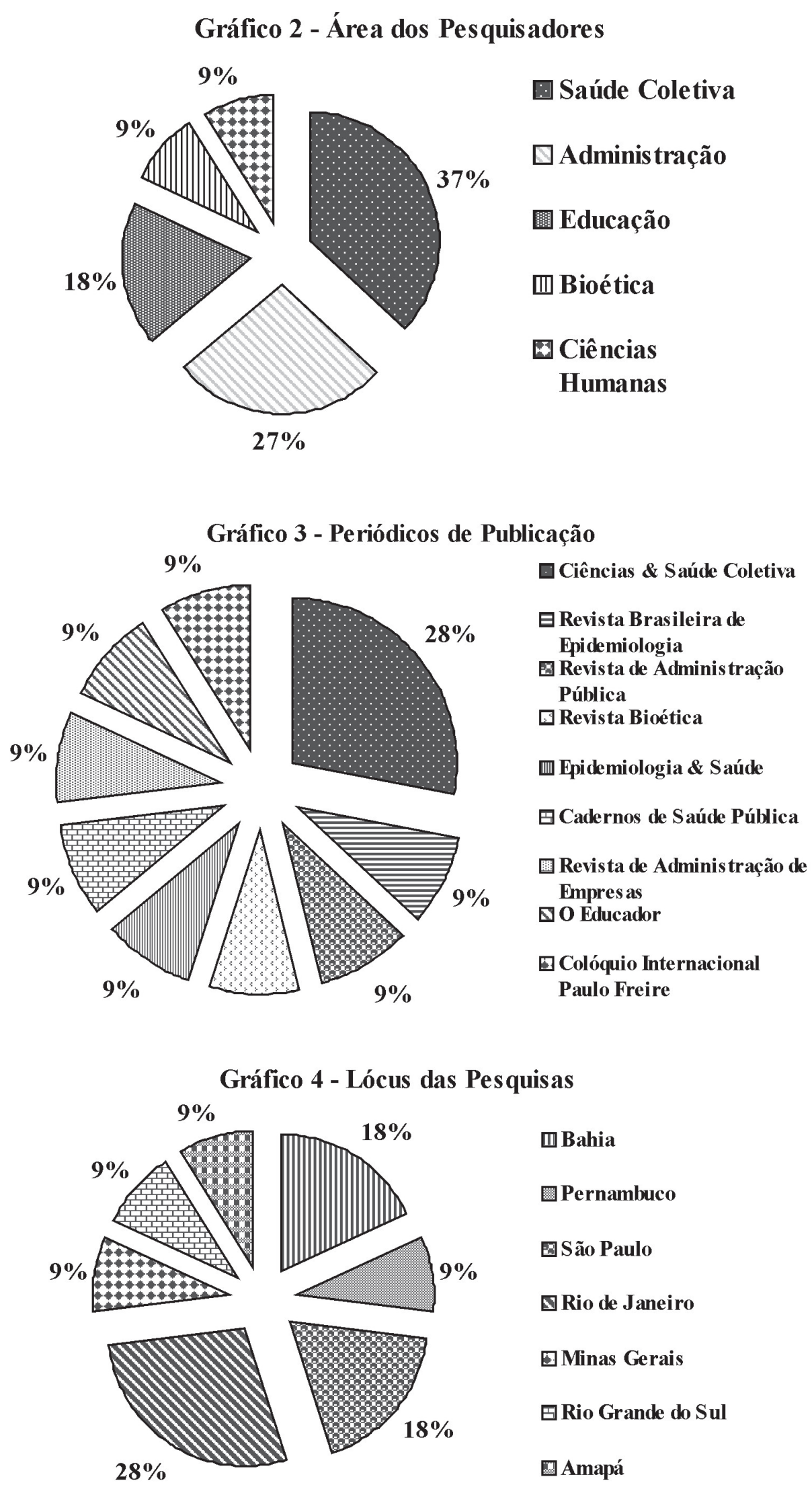
Bahia (18\%) e São Paulo (18\%). A região com maior número de produções é a Sudeste (55\%), seguida da Nordeste (27\%).

A metodologia utilizada nas produções científicas foi predominantemente $(100 \%)$ a abordagem qualitativa, o que observa o desinteresse dos pesquisadores em usarem a abordagem quantitativa ou associada qualitativa/ quantitativa na temática, sendo métodos também eficazes em pesquisas científicas.

\section{SUS: UTOPIA OU REALIDADE?}

O SUS pode ser realidade ou utopia com os seus princípios de equidade, descentralização e integralidade. É a impressão do sistema constitucional e legal brasileiro, de uma compreensão da saúde forjada em conceitos que em longo processo foi consolidada na saúde coletiva e na epidemiologia. A saúde pública reflete em todas as áreas de atuação e para que se constitua um trabalho de qualidade, é preciso analisar esses paradigmas que se encontram no SUS, o patrimônio do brasileiro. ${ }^{15}$

Os princípios e diretrizes do SUS não estão sendo cumpridos, apenas estão na Constituição Federal e nas LOS, por isso se pensa que o SUS é mais uma utopia, uma ilusão do que a realidade. A população brasileira é carente de um sistema de saúde que promova a saúde e previna os agravos com eficiência e eficácia.

Trevisan e Junqueira ${ }^{16}$ criticam a implementação da universalização e descentralização como uma pretensão constitucional num Estado que pensa em viver em constante "anemia induzida”. E concordam com Misoczky, ${ }^{17}$ do processo de "esculpir o SUS a golpes de portaria", pelo fato de o sistema ser operado por Normas Operacionais Básicas, onde o conceito de descentralização cai num processo de vácuo decisório, plenamente preenchido pela instância federal, porque a liberação é sempre um ato de Brasília e não de cada instância de governo, como é preconizado pela descentralização.

Nesse aspecto, Souza ${ }^{18}$ cita a diferença entre o SUS possível e o SUS necessário, o possível é o que temos hoje no sistema e o necessário é o SUS previsto na Constituição de 1988 e nas LOS, o que ainda está longe de se alcançar.

Acrescentando, Andrade e Andrade ${ }^{19}$ afirmam quanto ao SUS que: "A sua proposta inclusora cada vez mais parece ter forte vertente de exclusão, quando expulsa de seu seio a classe média e a classe trabalhadora".
Analisando o que Andrade e Andrade ${ }^{19}$ afirmam, podemos perceber isto no dia a dia, quando se dá prioridade a quem pode pagar por uma vaga na frente de filas de pessoas que não têm dinheiro e estão esperando atendimento de saúde há muitos meses.

Cerca de 42 milhões de brasileiros buscam a medicina suplementar como forma de assistência à saúde, um dos grandes paradoxos do sistema de saúde brasileiro. Muitas pessoas consideram um bom emprego aquele que lhes oferece um plano de saúde, a universalização proposta invariavelmente desaba na armadilha de racionamento de serviços e comprometimento da qualidade, estimulando o usuário a procurar outros planos. Mas como dizem Andrade e Andrade19: "As mazelas do SUS são as melhores mídias do sistema de saúde suplementar". Porque os dois se igualam por não terem recursos financeiros suficientes.

Assim, o objetivo do SUS seria só este sistema, quando se diz único, mas como não oferta os serviços de saúde com qualidade e quantidade suficiente para a sua demanda está dividindo espaços com serviços de saúde privados. Constituindo uma exploração da população brasileira, porque todos pagam de forma direta e indireta por este sistema que se diz único.

No entanto, a universalização é excludente, porque afasta as camadas médias e assalariadas e não oferta serviços de alta complexidade compatível com a camada mais pobre. Com esse quadro alarmante do sistema de saúde brasileiro, Paim ${ }^{20}$ identificou quatro sistemas diferentes do SUS: o SUS para o pobre, o SUS legal, o SUS real e o SUS democrático. No primeiro, o atendimento é possível, simplicista; o segundo SUS legal é regido por leis e normas; o SUS real é marcado pela falta de controle e a dificuldade de fiscalização, e o SUS democrático seria a vontade de todos. Esse SUS democrático que deveria existir e prevalecer como rege suas leis e diretrizes está se transformando na realidade, em uma verdadeira utopia, ou seja, uma alienação social.

Seria necessária a constituição de coalizões mais amplas para fazer cumprir a universalidade e igualdade, outro desafio é a definição do mix público/privado para garantir maior efetividade e sustentabilidade e por fim promover uma ressignificação do SUS para que ele não continue sendo o SUS para os pobre ${ }^{21}$ e o SUS utópico.

Tratando de utopia, alienação social, Santos ${ }^{22}$ aborda que o processo de desenvolvimento do SUS é dividido em rumos maiores e adicionais. Os rumos maiores do SUS significam as "chamas da 
utopia' e constituem os valores da saúde enquanto direito de cidadania, parte dos direitos universais dos seres humanos e o dever do Estado em prover os serviços de saúde de qualidade.

As chamas da utopia podem ser consideradas os princípios e diretrizes do SUS, a Constituição de 1988, as LOS, a Emenda Constitucional n ${ }^{\circ} 29$, que não estão sendo legisladas. Os rumos adicionais do SUS são os desejáveis: implementação concomitante e institucional dos princípios, modelos de atenção e de gestão com base nas necessidades e direitos da população, desenvolvimento de recursos humanos, relações público/privado, financiamento e participação social.

Entretanto, o SUS é considerado por outros autores com um sistema generoso e utópico, que busca assistência igualitária, digna e de qualidade, mas na prática permanece no sistema neoliberal de estado mínimo com baixa qualidade e difícil acesso. ${ }^{19}$ Pode ser visto como um modelo republicano cívico por sua capacidade, associado a outros esforços, de permitir o revigoramento junto a outras instituições. A democratização da saúde é uma utopia atual, que tem condições de construir e transformar o Estado e a sociedade brasileira. ${ }^{23}$

Além do sistema de saúde ser considerado utópico, o conceito de saúde pela Organização das Nações Unidas (ONU), logo após a Segunda Guerra Mundial, afirma que saúde é o mais completo estado de bem-estar físico, mental e social e não apenas ausência de enfermidades, supõe mais uma utopia do que algo a ser almejado, esse conceito foi influenciado pela Declaração de Alma-Ata que privilegiou a universalização. ${ }^{19}$

"O conceito de saúde reflete a conjuntura social, econômica, política e cultural. Ou seja: saúde não representa a mesma coisa para todas as pessoas". ${ }^{19}$ Levando em consideração fatores epidemiológicos, epistemológicos e psicanalíticos, esse conceito pode ser mais uma utopia do que realidade.

A saúde não é algo que pode se alcançar com tantos benefícios como físico, mental, social porque em cada um desses estão contidos vários entraves que paralisam o principal objetivo almejado, assim ninguém teria saúde se fosse considerar este conceito. Por isso, o SUS pode ser comparado a uma anemia induzida, como relataram alguns autores, devido a todos os conceitos que englobam o SUS, por ser algo mais desejável do que induzido, mas não alcançável, se tornando uma utopia.

As práticas utópicas são entendidas por Paulo Freire $^{24}$ da seguinte maneira: "Não utópica no sentido de irrealizável; não utópica no sentido de quem discursa sobre o impossível, sobre os sonhos impossíveis. Utópica no sentido de que esta é uma prática que vive a unidade dialética, dinâmica, entre a denúncia e o anúncio do sonho possível". A promoção da saúde pode somar novas utopias, quando retoma e aprofunda as promessas da RSB e boas práticas do SUS, bem como seus princípios.

O diferencial da promoção da saúde entre ser um instrumento de neoliberalismo ou de mais equidade é a participação social. Nesta perspectiva, a promoção da saúde está colocada em base de mobilização, com ênfase na atuação e corresponsabilização, onde a capacitação e o desenvolvimento de estratégias visam articular a população, controlando sua saúde e condição de vida, tanto individual, quanto coletivo em busca da assistência de qualidade pelas políticas e serviços de saúde. ${ }^{25}$

A utopia pode ser uma coisa irreal, imaginária, mas também, uma coisa idealizada, a qual queremos no presente ou no futuro. Neste contexto, observamos que o SUS constitui uma utopia de acordo as suas legislações, as quais preconizam vários benefícios, princípios, diretrizes e parcerias que deveriam propor um serviço de saúde de qualidade, que atendessem à demanda da população brasileira. Por que os brasileiros pagam impostos, uma parte dos recursos vai para o funcionamento do SUS, e isso não lhe garante a seguridade social esperada.

\section{Conclusão}

O cenário deste estudo constituiu-se na maior parte de artigos científicos (82\%) publicados no período de 2007-2010 (65\%), na área da Saúde Coletiva (37\%), no periódico Ciência \& Saúde Coletiva (28\%), realizadas no Estado do Rio de Janeiro (28\%), na região Sudeste $(55 \%)$ e com abordagem metodológica predominantemente qualitativa (100\%).

As produções científicas analisadas evidenciam que o SUS é considerado utopia, alienação social, nas seguintes vertentes: princípios e diretrizes como universalização, equidade, integralidade, descentralização, além do controle social, das normas operacionais, da relação público/privado, da promoção da saúde e do conceito de saúde. E também que o SUS avançou pouco desde seu processo de implementação e precisa superar todas essas utopias, tornando-as realizáveis por meio do cumprimento de todas as legislações e normas vigentes no sistema de saúde brasileiro e por meio da implementação de políticas públicas e estratégias que sensibilizem a participação dos atores sociais que compõem este sistema. 


\section{REFERÊNCIAS BIBLIOGRÁFICAS}

1. Brasil. Ministério da Saúde. O Sistema Público de Saúde Brasileiro. Seminário Internacional: Tendências e Desafios dos Sistemas de Saúde nas Américas. São Paulo; 2002.

2. Agência Saúde. SUS Completa 20 anos com Novos Desafios: Entrevista concedida pelo Ministro da Saúde José Gomes Temporão à Agência Saúde. Rev. Saúde Pública 2008 jan-jun;1(1):7-9.

3. Mendes EV. Uma Agenda Para a Saúde. 2 ed. São Paulo: Hucitec; 1999.

4. Brasil. Conselho Nacional de Secretários de Saúde. SUS: avanços e desafios. 1 ed. Brasília: CONASS; 2006.

5. Ferreira JAV. Planejamento em saúde: dificuldades na implantação do SUS. Trabalho apresentado no curso de Especialização em Saúde Pública (edição 1999). Rio Grande do Sul: UFRGS; 1999.

6. Silva PLB. Serviços de Saúde: o dilema do SUS na nova década. São Paulo Perspec. 2003;17(1):69-85.

7. Barros E. O Controle Social o Processo de Descentralização dos Serviços de Saúde. In: Brasil. Ministério da Saúde. Incentivo a Participação Popular e o Controle Social no SUS: textos técnicos para conselheiros de saúde. Brasília: IEC; 1994. Cap. 3. P. 29-37.

8. Jorge EA. Financiamento setorial do SUS e a questão da municipalização saúde. In: Brasil. Ministério da Saúde. Incentivo à Participação Popular e o Controle Social no SUS: textos técnicos para conselheiros de saúde. Brasília: IEC; 1994. Cap.5. P. 45-54.

9. Cohn A. A reforma sanitária brasileira após 20 anos do SUS: reflexões. Cad. Saúde Pública 2009 jul;25(7):1614-19.

10. Maio MC, Lima NT. Fórum: O desafio SUS: 20 anos do Sistema Único de Saúde. Introdução. Cad. Saúde Pública 2009 jul;25(7):1611-13.

11. Paim JS, Teixeira CF. Configuração Institucional e gestão do Sistema Único de Saúde: problemas e desafios. Ciênc. Saúde Colet. 2007;12 suppl 1:1819-29.

12. Triviños ANS. Introdução à pesquisa em ciências sociais: a pesquisa qualitativa em educação. 1 ed. 14 reimpressão. São Paulo: Atlas; 2006.
13. Bardin L. Análise de Conteúdo. Lisboa: Edição 70; 1977.

14. Brasil. Lei no .9 .610 de 19 de fevereiro de 1998. Altera, atualiza e consolida a legislação sobre direitos autorais e dá outras providências. Diário Oficial da União, n. 36, seção 1, p. 3-9, Brasília: 20 de fevereiro 1998.

15. Barreto ML. Papel da epidemiologia no desenvolvimento do Sistema Único de Saúde no Brasil: históricos, fundamentos e perspectivas. Rev. Bras. Epidemiol. 2002;5 suppl 1.

16. Trevisan LN, Junqueira LAP. Construindo "o pacto de gestão" no SUS: da descentralização tutelada à gestão em rede. Ciênc. Saúde Colet. 2007 jul-ago;12(4):893-902.

17. Misoczky MC. Redes e hierarquias: uma reflexão sobre arranjos de gestão na busca da equidade e saúde. Rev. Adm. Pública 2003 mar-abr;37(2):335-54.

18. Souza LEPF. O SUS necessário e o SUS possível: estratégias de gestão. Uma reflexão a partir de uma experiência concreta. Ciênc. Saúde Colet. 2009;14(3):911-18.

19. Andrade EM, Andrade EO. O SUS e o direito à saúde do brasileiro: leitura de seus princípios com ênfase na universalidade da cobertura. Revista Bioética 2010; 18(1): 61-74.

20. Paim JS. Políticas de descentralização e atenção primária à saúde. In: Rouquayrol MZ, Almeida Filho N (org.). Epidemiologia \& Saúde. Rio de Janeiro: Medsi; 2003.

21. Menicucci TMG. O Sistema Único de Saúde, 20 anos: balanço e perspectivas. Cad. Saúde Pública 2009 jul;25(7):1620-25.

22. Santos NR. Desenvolvimento do SUS, rumos estratégicos e estratégias para visualização dos rumos. Ciênc. Saúde Colet. 2007;12(2):429-35.

23. Teixeira SMF. Retomar o Debate sobre a Reforma Sanitária para Avançar o Sistema Único de Saúde (SUS). Rev. Adm. Empres. 2009 out-dez;49(4):472-80.

24. Freire P. Educação. O sonho possível. In: Brandão CR (org.). O educador: vida e morte. Rio de Janeiro: Graal; 1985. p. 89-101.

25. Marcondes WB. Multiculturalidade, Autonomia e Participação Popular na Promoção da Saúde. In: V Colóquio Internacional Paulo Freire. Relatos de experiências 2005; 11 p. 